\title{
O ENSINO DO EXAME FÍSICO EM SUAS DIMENSÕES TÉCNICAS E SUBJETIVAS
}

\author{
Carlos Magno Carvalho da Silva1, Vera Maria Sabóia², Enéas Rangel Teixeira ${ }^{3}$
}

\footnotetext{
${ }^{1}$ Mestrando do curso de Mestrado Acadêmico em Ciências do Cuidado em Saúde. Escola de Enfermagem Aurora de Afonso Costa (EEAAC). Universidade Federal Fluminense (UFF). Rio de Janeiro, Brasil. E-mail: mcarvalho27@yahoo.com.br

2 Doutora em Enfermagem. Professor Titular do Departamento de Fundamentos de Enfermagem e Administração da EEAAC/ UFF. Rio de Janeiro, Brasil. E-mail: verasaboia@uol.com.br

${ }^{3}$ Doutor em Enfermagem. Professor Titular do Departamento de Enfermagem Médico Cirúrgica da EEAAC/UFF. Rio de Janeiro, Brasil. E-mail: eneaspsi@hotmail.com
}

RESUMO: Pesquisa qualitativa, descritiva e exploratória, cujos objetivos foram descrever as concepções dos acadêmicos de enfermagem sobre a prática do exame físico destacando as dimensões subjetivas e discutir o ensino desta prática na perspectiva do cuidado clínico de enfermagem. Utilizou-se como técnicas para coleta de dados a entrevista semiestruturada direcionada a acadêmicos do quarto período do Curso de Enfermagem, e a observação participante, realizada durante a consulta realizada por estes sujeitos sob o auxílio de professores, monitores e enfermeiros. Os relatos dos acadêmicos foram analisados à luz da hermenêutica-dialética e agrupados em categorias - a comunicação interpessoal; a ética e a estética do corpo e as tecnologias envolvidas no ensino. A atividade do exame físico precisa considerar sua complexidade relacional e técnico-científico, viabilizando a humanização do cuidado de enfermagem.

DESCRITORES: Exame Físico. Ensino. Enfermagem. Psicologia. Relações interpessoais.

\section{TEACHING THE PHYSICAL EXAMINATION IN ITS TECHNICAL AND SUBJECTIVE DIMENSIONS}

\begin{abstract}
The objective of this qualitative, descriptive, and exploratory study was to describe nursing students' conceptions of the physical examination practice, highlighting its subjective dimensions and discussing the teaching of this practice baesd on clinical nursing care. Techniques for data collection included semi-structured interviews of fourth semester Nursing students and peer observation, performed with the aid of teachers, monitors, and nurses. The students' reports were analyzed according to hermeneuticdialectics and grouped into the following categories: interpersonal communication; ethics and aesthetics of the body; and technologies involved in teaching. The activity of physical examination must consider its relational and technical-scientific complexity, promoting the humanization of nursing care.
\end{abstract}

DESCRIPTORS: Physical examination. Teaching. Nursing. Psychology. Interpersonal relations.

\section{LA ENSEÑANZA DEL EXAMEN FÍSICO, SUS DIMENSIONES TÉCNICAS Y SUBJETIVAS}

RESUMEN: Es una investigación cualitativa, descriptiva y exploratoria, cuyos objetivos fueron describir los conceptos de los estudiantes de enfermería sobre la práctica del examen físico haciendo hincapié en la dimensión subjetiva y discutir la enseñanza de esta práctica en la perspectiva clínica de cuidados de enfermería. Como técnica de recolección de datos se utilizó la entrevista semiestructurada, dirigida a los estudiantes del cuarto período del curso de enfermería, y la observación participante, realizada durante la consulta conducida por estos sujetos, asistidos por profesores, tutores y enfermeros. Los informes de los estudiantes fueron analizados a luz de la hermenéutica-dialéctica y agrupados en categorías comunicación interpersonal, la ética y la estética del cuerpo y las tecnologías que intervienen en la educación. La actividad del examen físico debe considerar su complejidad relacional y técnico científica, permitiendo la humanización de la atención de enfermería.

DESCRIPTORES: Examen físico. Enseñanza. Enfermería. Psicología. Relaciones interpersonales. 


\section{INTRODUÇÃO}

Este estudo tem por objeto de investigação o ensino do exame físico no Curso de Graduação em Enfermagem e os consequentes processos de subjetividade que emergem durante o ensino e a aprendizagem deste conteúdo.

O exame físico, realizado pelo enfermeiro no intuito de trazer à tona as necessidades humanas, é dotado de subjetividade, partindo do pressuposto que o corpo integra uma complexidade, na qual sua realidade biológica está inserida na espécie humana, na cultura e na organização social. ${ }^{1}$

Nesta perspectiva, o corpo é um substrato vivo e desejante no qual agem multiformes modelagens culturais. Com efeito, através dos sinais corporais, é possível perceber características comuns a todo ser humano, de acordo com seu contexto geográfico e histórico, como expressões de alegria, tristeza, medo, surpresa, entre outros. No entanto, nas pessoas manifestam-se diferenciações anatômicas, fisiológicas e psíquicas, que as diferenciam, atribuindo-lhes especificidades. ${ }^{2}$

O corpo humano, inserido em uma malha social, está sujeito a um controle que se processa em um contexto político, econômico e cultural, sendo que suas formas se sofisticam e variam ao longo do tempo. Tal processo não ocorre apenas por meio da repressão sobre os impulsos naturais, mas por construções de práticas e representações que se difundem no imaginário por sofisticadas e sutis estratégias, criando noções sobre o corpo, a pessoa e a natureza. Neste contexto, as práticas de saúde são instrumentos do processo e precisam ser percebidas pelo enfermeiro no cuidado com o corpo.

A concepção do corpo sob o ponto de vista patológico, provém de uma perspectiva mecanicista, dualista e positivista, que não contempla a complexidade do processo de subjetivação e a dimensão relacional do cuidar em enfermagem. Esta racionalidade mecanicista pressupõe que "como qualquer objeto natural, a saúde e a doença podem ser explicadas exclusivamente pela interação mecânica das diferentes partes do organismo humano". ${ }^{3: 310}$ Neste sentido, não há o reconhecimento do papel da sociedade, da cultura e da história do sujeito na produção da saúde ou da doença.

Destarte, ressalta-se a necessidade de aprofundamento nestas questões referentes ao ensino do exame físico na graduação em enfermagem, a fim de contribuir para a construção da clínica de enfermagem considerando sua especificidade e dimensão transdisciplinar, rompendo, desta forma, com o modelo hegemônico na saúde. Esta compreensão da saúde enfoca o sujeito de modo contextualizado, enfatiza o trabalho interdisciplinar e transdisciplinar, preconiza a relação entre a saúde e as condições biológicas, psicológicas, o contexto social e a produção de saberes e práticas. ${ }^{1}$

O olhar do profissional pode apresentar diferentes vertentes, como demonstra a compreensão do campo clínico pelas objetividades sem e entre parênteses. $^{4}$

Durante a observação da objetividade sem parênteses, os sinais obtidos através das técnicas semiológicas de inspeção, palpação, percussão e ausculta expressam o corpo dessubjetivado, desvinculado-o da vivência e do contexto social. ${ }^{4}$ Logo, "a linguagem do sujeito só tem valor como subsídio para elucidar o diagnóstico pautado no modelo da doença". 5:363

Entretanto, a objetividade entre parênteses possibilita a percepção dos aspectos existentes nas entrelinhas dos sinais e sintomas, indissociáveis à história de vida. Por conseguinte, o sintoma corporal pode expressar um estado de tensão emocional, evidenciado durante o exame físico, que precisa ser incluído como elemento de avaliação no cuidado. ${ }^{5}$

A atenção complexa ao paciente está presente em toda a interação com o enfermeiro, o que permite, durante o exame físico, a união da técnica semiológica e a parte tecnológica que são essenciais para o êxito do exame físico.

As tecnologias podem ser classificadas segundo a característica de sua instrumentalidade no contexto da saúde. A tecnologia dura é representada pelos equipamentos tecnológicos do tipo máquinas, normas e estruturas organizacionais. A tecnologia leve-dura envolve os saberes estruturados, ou seja, os princípios científicos que regem de certa maneira os equipamentos e seu uso. Já a tecnologia leve remete à tecnologia das relações, de encontros de subjetividades, de produção de vínculo, autonomia e o acolhimento. Esta se relaciona com o saber que as pessoas adquirem e se apropriam no modo de pensar e atuar sobre a saúde. ${ }^{6}$

A técnica - composta da tecnologia - é um "conjunto de processos de uma arte; a maneira ou habilidade especial de executar ou fazer algo específico de determinada profissão" ${ }^{\text {7:6 }}$ No caso do exame físico de enfermagem, este envolve técnicas, manuais e instrumentais, que seguem embasamentos científicos, efetuadas por profissionais que construíram conceitos sobre este fazer, 
direcionado a pessoas (pacientes) com necessidades específicas, resultantes de um histórico de influências ambientais.

Durante o Curso de Graduação em Enfermagem, o acadêmico é treinado para realizar as técnicas de modo eficiente, avaliado e cobrado em relação à concretização desta meta. Durante este processo, suas reações psicológicas afloram através de sentimentos de insegurança, medo, respeito, passividade, incerteza.

A problemática do estudo trata das implicações no processo de ensino-aprendizagem do exame físico, que amiúde, é enfocado numa perspectiva diagnóstica, valorizando a doença e não as condições de saúde ou a pessoa em si.

Além disto, neste processo, é possível ocorrer um bloqueio psicológico que impede o acadêmico de exercer, da melhor maneira a composição técnica-tecnologia, cabendo ao professor uma relação de ajuda para construir juntamente com o acadêmico os saberes pertinentes ao exame físico de forma dinâmica. Por conseguinte, a perspectiva transdisciplinar aparece na fundamentação do cuidado, permitindo que o mesmo não seja concebido de forma linear, mas que seja compreendida a complexidade do processo, as intervenções das instituições de saúde, da mídia, da cultura, da religião e de outros elementos de ressonância na malha social que repercutem na saúde do indivíduo. ${ }^{8}$

É evidente que o domínio da técnica é relevante para o exame físico, bem como a consideração da subjetividade que surge durante o processo, visto que o cuidado sensível que compõe a arte na enfermagem não dissocia técnica e tecnologia. ${ }^{1}$

Diante das considerações iniciais, definem-se os objetivos do estudo:

1. Descrever as concepções dos acadêmicos de enfermagem sobre a prática do exame físico destacando suas dimensões subjetivas;

2. Discutir o ensino desta prática na perspectiva do cuidado clínico de enfermagem.

\section{METODOLOGIA}

Utilizou-se a abordagem qualitativa por ser direcionada para a investigação dos significados das relações humanas, expressos por subjetividades e sentimentos aflorados nas situações vivenciadas no dia-a-dia. ${ }^{9}$

A pesquisa é descritiva e exploratória. Os estudos descritivos preocupam-se com a narra- ção circunstanciada das características de dada população, em determinado campo. ${ }^{10} \mathrm{O}$ caráter exploratório proporciona maior familiaridade com o problema com vistas a torná-lo explícito ou a construir hipóteses. Envolve levantamento bibliográfico, entrevistas com pessoas que tiveram experiências práticas com o problema pesquisado e análise de exemplos que estimulem a compreensão. Portanto, a pesquisa exploratória permite aumentar a experiência em torno do problema, permitindo explorar tipicamente o objeto de estudo, visando criar maior familiaridade em relação a um fato ou fenômeno. ${ }^{11}$

Para contextualização teórica, foi realizada uma pesquisa de artigos nas principais bases de dados em saúde. Utilizando os unitermos exame físico e enfermagem, 992 resultados foram encontrados em bases como a LILACS - Literatura Latino-Americana e do Caribe em Ciências da Saúde (84), MEDLINE - Literatura Internacional em Ciências em Saúde (891) e SciELO - Scientific Electronic Library Online (17) configurando um resultado consistente. Contudo, este número é reduzido quando se fala em artigos que abordam o ensino e aprendizagem deste conteúdo (formação) com 47 resultados: LILACS (21), MEDLINE (21), SciELO (5).

O universo da pesquisa compreendeu uma turma de acadêmico do $4^{\circ}$ período da graduação em enfermagem, com aproximadamente 50 alunos, durante o curso da disciplina Fundamentos de Enfermagem. O ensino do exame físico nesta fase é dividido em blocos teóricos e práticos. Dentre os diversos campos práticos, foi escolhido o Ambulatório do Hospital Universitário Antônio Pedro (HUAP) da Universidade Federal Fluminense (UFF), mais precisamente a consulta de enfermagem desenvolvida com pacientes diabéticos, para a observação sistemática da realização do exame físico pelos acadêmicos, bem como sua interação com os pacientes.

Os sujeitos estudados foram 20 acadêmicos, quatro do sexo masculino e 16 do feminino, com idade entre 20 e 27 anos, pertencentes à mesma turma de graduação. Como critérios de inclusão, os sujeitos deveriam estar inscritos na disciplina de Fundamentos de Enfermagem durante o $2^{\circ}$ semestre de 2007 e concordar com a participação na pesquisa assinando do Termo de Consentimento Livre e Esclarecido. Estes são identificados no estudo pela inicial A (acadêmico). Assim, onde estiver expresso, por exemplo, A1, lê-se acadêmico 1, cujas falas são registradas nos resultados em itálico.

$\mathrm{Na}$ fase de coleta de dados foram realizadas 48 horas de observação participante, além de en- 
trevistas individuais que duraram 25 minutos, em média. A entrevista, semiestrurada, consistiu-se de um roteiro previamente elaborado que serviu de eixo orientador ao desenvolvimento da entrevista, e procurou as respostas dos participantes às mesmas questões, não exigindo ordem rígida, mantendo um grau de flexibilidade, adaptando-se ao entrevistado e permitindo assim, o aprofundamento da temática estudada. ${ }^{9}$

Os acadêmicos foram questionados sobre a preparação para a realização do exame físico, os instrumentos necessários, a subjetividade do paciente, os sentimentos e preocupações emergentes da interação. Os depoimentos foram gravados em aparelho de tecnologia Mp3 e transcritos na íntegra pelos pesquisadores em um hipertexto.

Em seguida, foi realizada a leitura flutuante das respostas, confrontada com os objetivos. Para análise das falas, utilizou-se a hermenêuticadialética, por ser capaz de "[...] dar conta de uma interpretação aproximada da realidade" ${ }^{12: 231}$ Esta técnica analítica relaciona o depoimento ao seu contexto, para entendê-lo a partir do seu interior e no campo da especificidade histórica e totalizante em que é produzido. ${ }^{12}$

A partir da análise, os dados foram organizados, segundo suas unidades de significação, nas seguintes categorias temáticas: a comunicação interpessoal, a ética e a estética do corpo e as tecnologias envolvidas no ensino.

A pesquisa obteve parecer favorável do Comitê de Ética em Pesquisa da Faculdade de Medicina/ HUAP, emitido em 09/11/07, com o No 0126025800007 e obedece aos preceitos da Resolução Nº 196/96 do Conselho Nacional de Saúde, que regulamenta a pesquisa envolvendo seres humanos.

\section{RESULTADOS E DISCUSSÃO}

\section{A comunicação interpessoal}

O profissional que realiza o exame físico não deve ser mero executor da técnica ou cumpridor de tarefas. É importante buscar uma relação interpessoal, na qual tem importância não só os conhecimentos do enfermeiro relativos à doença, como também aspectos humanísticos, éticos e sociais. Desta forma, percebe-se o ser cuidado e a doença é considerada como expressão dos condicionantes sociais, culturais, econômicos e próprios de cada ser, como é possível perceber na fala do acadêmico.

O exame físico trata do toque, da observação, um paciente emocionalmente instável pode se revelar durante o toque realizado ao exame, por exemplo, se este já tiver sofrido alguma experiência traumática como estupro (A12).

O corpo é uma estrutura autônoma, funcional e expressiva. Mesmo quando os pacientes não verbalizam suas queixas e sentimentos, a postura e a expressão expõem a realidade corporal percebida pelos acadêmicos: às vezes, só o fato do paciente assumir uma posição retraída, já me mostra algo do comportamento dele (A3).

Quando se realiza a entrevista, o exame físi$\mathrm{co}, \mathrm{o}$ banho no leito ou qualquer que seja o cuidado prestado a um paciente consciente ou não, o seu corpo revela sinais e signos objetivos ou subjetivos. ${ }^{13}$ A expressão corporal se afirma no mundo e na comunidade, nos quais o corpo expressivo se integra e interage.

O contato proporcionado pelo exame físico permite conhecer o paciente, facilita a comunicação e o cuidado humanizado. Assim, a estimulação tátil tem efeitos profundos sobre o organismo, tanto fisiológicos quanto comportamentais. ${ }^{14} \mathrm{O}$ toque é um aspecto da comunicação não-verbal, talvez a sua faceta mais importante para transmitir empatia e segurança. ${ }^{15}$ Pode ser adotado para manter a atenção de uma pessoa, transmitir cuidado e conforto. $\mathrm{O}$ depoimento do acadêmico evidencia esta consideração.

O toque ajuda na proximidade do profissional com o paciente, além de ajudar na detecção de problemas físicos que podem estar relacionados a questões subjetivas (A10).

Os profissionais de enfermagem têm muitas oportunidades de tocar o paciente de modo a transmitir expressões sentimentais que podem despertar no cliente reações agradáveis ou não, dependendo de sua cultura e valores. ${ }^{16}$ Deste modo, os acadêmicos reconhecem a importância do toque na comunicação não verbal.

Se eu fosse paciente, gostaria de ser tocada, pois mostra que o profissional se importa comigo. Tem profissional que nem mesmo olha pra você (A13).

$\mathrm{Na}$ Enfermagem, a forma como se toca um paciente pode ser diferenciada. $\mathrm{O}$ toque instrumental é um contato físico deliberado e necessário para o desempenho de uma tarefa específica, como a verificação de pulso e temperatura. Durante o toque expressivo ou afetivo, sua finalidade pode compreender a afetividade, empatia, apoio, segurança e proximidade em relação ao paciente, de acordo com as normas éticas da profissão. Já o toque terapêutico, resulta na técnica de imposição 
das mãos aplicada como medida terapêutica para atuar no campo da energia humana. ${ }^{17}$

Ao tocarmos uma pessoa, quebramos a barreira dos espaços impostos por ela, há uma exposição, uma vulnerabilidade. No entanto, o trabalho do enfermeiro é ético e terapêutico, não visa tornar as pessoas vulneráveis no intuito de constrangê-las, mas para que, o relacionamento dinâmico enfermeiro-paciente tenha finalidade terapêutica. ${ }^{18}$

Para os acadêmicos é possível perceber a abertura dada pelo paciente ao ser tocado. Durante o toque, o paciente se coloca extremamente sensivel e fragilizado. Posso aproveitar este momento para demonstrar que estou ali para cuidar dele e não para fazer ele passar por algum constrangimento (A9).

$\mathrm{O}$ exame físico proporciona um momento oportuno para que seja realizado o toque terapêutico. Entretanto, muitas pessoas se fecham para este contato técnico-profissional, porém acolhedor. Em contrapartida, ao se sentirem acolhidas, passam a entender a necessidade da realização do procedimento e permitem a interação.

O acolhimento consiste na humanização das relações entre enfermeiros e usuários. $\mathrm{O}$ encontro entre estes sujeitos durante a consulta produz uma relação de escuta e responsabilização, a partir da qual são constituídos vínculos e compromissos que norteiam os projetos de intervenção e cuidado. Este espaço permite que o enfermeiro use de sua principal tecnologia, o saber, tratando o usuário como cidadão. O acolhimento constitui-se numa tecnologia leve para a humanização do atendimento. ${ }^{19}$

Percebe-se expressões de acolhimento na seguinte fala do depoente: [...] por se tratar de um momento de contato com o paciente, pode ser aproveitado como um momento de estreitamento de laços e posterior descoberta de tais necessidades (A11).

Também são evidenciadas as oportunidades de interação no momento do exame pelo acadêmico: neste momento, mesmo que o exame físico não apresente nenhuma alteração, estamos juntamente com o paciente, conversando, trocando informações. E, neste momento, o paciente reconhece o seu trabalho e confia em você [...], ele desabafa e fala a gênese daquela patologia (A8).

Durante o exame físico o processo de comunicação interpessoal é possível. No entanto, enfermeiros e acadêmicos devem ter a consciência da relação dos comportamentos verbais e não-verbais nas interações, e reconhecer as emoções, expectativas e os estereótipos que interferem na comunicação. ${ }^{20}$

Cuidar de modo transformador é permitir a interação, a troca, e perceber o outro na sua inte- gralidade. Esta experiência permite não somente a realização do trabalho do enfermeiro, mas proporciona o bem estar físico e mental do paciente no processo do cuidado.

\section{A ética e a estética do corpo}

Os acadêmicos percebem a questão da aproximação com o paciente através do toque como algo importante para o bom desenvolvimento das relações humanas, aderência e continuidade do cuidado. No entanto, permeiam por este relacionamento questões relativas à ética e à estética, destacadas pelos acadêmicos.

Tocar no corpo de outra pessoa é algo que encabula. Tem que fazer de forma muito respeitosa tan to para quem toca quanto para quemé tocado. Portanto, sempre explico o que vou fazer e respeito os limites de cada um (A7).

A palavra estética é proveniente do grego aisthetiké, que por definição se refere ao que pode ser percebido pelos sentidos..$^{21}$ De modo correlato, a estética é percebida como "[...] a teoria do belo e das suas manifestações através da arte". ${ }^{21: 1}$ Nesta óptica, o campo do conhecimento estético propõe o alcance do saber sensível, contrapondo-se às disciplinas que têm a razão como premissa e que pretendem estabelecer o conhecimento claro e distinto, conforme o ideal de saber cartesiano, considerando, assim, as percepções dos sujeitos, suas ações, a preservação da integridade no cuidado e a arte. ${ }^{21}$

A sensibilidade ao mesmo tempo em que remete às sensações, ao subjetivo, expressa a afetividade do cuidado, que pode ser traduzida pela relação de ajuda, de respeito, de amor. ${ }^{8}$ Deste modo, "a cuidadora deve estar sensibilizada e habilitada para ajudar e apoiar nas circunstâncias de vulnerabilidade e, nesse sentido, o cuidar tem seu ponto de máxima importância, pois os esforços para buscar a restauração vão além da ordem física, representando apoio e permitindo que o outro, o ser cuidado, seja ele mesmo, em sua própria especificidade, em sua singularidade". 22:766

A técnica, a estética e a ética se articulam no cuidado para preservar a singularidade do cliente, aspecto ressaltado pelo seguinte depoimento: inicialmente, fico insegura, com medo de machucar ou até invadir a privacidade do paciente (A3).

Assim, há a preocupação com o cuidado desenvolvido, registrada pela afirmação do acadêmico: no início, me senti mal, por achar que estava invadindo a privacidade dos outros, ou machucando, mas no final vi que estava mesmo é contribuindo para o cuidado (A1). 
A estética envolve o "[...] cuidado com a vida, é banhada de desejo e de satisfação, motiva o sujeito a cuidar-se e faz com que ele se sinta atraente, bonito e mais jovem; o cuidado com o corpo é, portanto, estético". 23:106

A dimensão estética se traduz por bem estar e conforto, demonstrada pelos acadêmicos de enfermagem, que expressam suas preocupações em relação aos sentimentos dos clientes: tenho um pouco de receio em relação ao conforto do paciente, se ele está se sentindo bem com a situação (A2).

A ética vem ao encontro do cuidado sensível, orientando sobre as possibilidades e limites na interação entre cliente e enfermeiro, preservando o respeito, a fim de que o afeto atenda a dimensão terapêutica do cuidado, como demonstra o seguinte depoimento: muitas vezes me sinto invadindo a intimidade dos pacientes, porém eles se demonstram acostumados com a situação. A forma de tocar faz toda diferença (A9).

Destaca-se ainda que, a ética na enfermagem contemporânea não tem um caráter rígido de ordem, limitação e hierarquia. Esta atitude ética leva à honestidade e aperfeiçoa o cuidado de modo solidário. ${ }^{24} \mathrm{O}$ indivíduo passa a ser tratado não como um objeto, mas como um ser provido de afeto e capacidade de decisão.

De tal maneira, o acadêmico percebe que, para exercer a profissão escolhida, ele também precisa assumir responsabilidades para com seus pacientes e considerar as decisões deles para o bom desenvolvimento do tratamento.

Sinto-me com uma responsabilidade imensa. Mas mesmo assim, é importante que eu aprenda junto com o paciente a cuidar dele e tocar no corpo com respeito (A12).

O contexto ético e estético no cuidado com o corpo busca o resgate dos aspectos humanos e da subjetividade para que o corpo assuma um papel social de transformação.

A dimensão estética do cuidado não pode ser considerada secundária a outras modalidades do cuidado, mas como outra forma de competência, que redimensiona as práticas de cuidados diretos e indiretos com o corpo. Esta abordagem abre margem para a criatividade, o valor da vida, os sentimentos e a ecologia no cuidado. A sensibilidade, neste sentido, vem contribuir de modo eficaz para a prática do cuidado em termos de relações humanas, trabalho e novas tecnologias. ${ }^{7}$

\section{As tecnologias envolvidas no ensino}

A problemática que envolve o ensino do exame físico atualmente está na valorização da realização da técnica por si mesma ao invés da conjunção do saber técnico científico com as subjetividades e transversalidades do cuidado, que constitui a clínica ampliada de enfermagem. O acadêmico se sente, então, pressionado a realizar as técnicas, quando poderia assumir uma postura crítica, como observado: fico insegura por talvez não estar desenvolvendo as técnicas corretamente (A10).

Tal fato é associado à forma verticalizada de ensino, onde o professor detém o conhecimento e o acadêmico é um mero receptor de informações. Sabóia ${ }^{25}$ apresenta as minúcias das técnicas do poder disciplinar enquanto atinge o plano da organização da vida íntima dos indivíduos. Elas adquirem importância à medida que definem uma nova microfísica do poder. Trata-se de pequenas astúcias, dotadas de grande poder de difusão, detalhes sutis, aparentemente inocentes, mas profundamente suspeitas e comuns a todas as instituições disciplinares. A infantilização, a culpabilização e o olhar que julga o outro são alguns destes subterfúgios.

Ainda é frequente o relacionamento vertical entre professor e acadêmico durante o processo ensino-aprendizagem, com o estabelecimento de relações unilaterais. Tal postura prejudica o crescimento e o desenvolvimento do estudante universitário como ser adulto, com um agravante este não se sente bem em ser tratado como criança, como é percebido na seguinte consideração: é bom poder aprender com os erros, voltar, discutir com o professor e fazer de novo, ao invés do professor tomar a frente e apenas mostrar como se faz. Os pacientes sabem que somos alunos e estamos ali para aprender (A16).

$\mathrm{O}$ acadêmico pode encontrar dificuldade no aprendizado diante dos seguintes aspectos: execução das técnicas; receptividade do paciente; avaliação dos professores; seus sentimentos, como o medo, insegurança e timidez. Esta situação foi bem caracterizada no estudo, devido também ao fato dos depoentes cursarem o $4^{\circ}$ período da graduação, quando têm seus primeiros contatos com a prática: me sinto insegura por não ter prática e destreza para ter total certeza das ações realizadas (A5).

Por conseguinte, o processo de ensino aprendizagem, que deveria ser um momento produtivo, pode trazer ao acadêmico, situações de constrangimento e outros sentimentos negativos, como é possível destacar no depoimento: tenho medo, muitas técnicas ainda não consigo realizar com facilidade, não consigo diferenciar um quadro patológico de um normal [principalmente coração e pulmão]. E se eu errar na frente do paciente? (A15). 
O estudo compreende que na prática do exame físico, as dimensões relacionais, subjetivas, complexas e humanas ainda são pouco trabalhadas durante o ensino deste conteúdo, que abarca saberes, técnicas, corpo, psiquismo e sociedade. De modo que nesta perspectiva de tecnologias, tais dimensões se definem por tecnologias sofisticadas, sutis e leves.

Os cursos da área de saúde são direcionados para um processo de ensino-aprendizagem centrado na competência profissional, deixando a desejar em aspectos críticos e afetivos para o desenvolvimento do aluno, não se constituindo em um processo de autoconstrução. Portanto, é dificultada ao acadêmico a possibilidade de reflexão sobre as suas experiências de vida. ${ }^{5}$

As dificuldades relacionadas aos sentimentos que surgem durante este processo precisam ser trabalhadas pelo aluno em conjunto com o professor, a fim de que não seja um obstáculo ao crescimento do futuro profissional. O professor precisa estar atento, sensível e preparado para não desperdiçar a oportunidade que os próprios acadêmicos apresentam diante da imprevisibilidade no cuidado clínico.

O papel de professores e monitores consiste em apoiar o acadêmico neste início da prática de enfermagem. Este por sua vez deve aproveitar as oportunidades e ter iniciativa para construir o conhecimento de modo interativo com o paciente, o professor e a equipe de saúde. ${ }^{26}$

A Enfermagem é uma disciplina constituída por saberes e práticas, no entanto seu exercício com os pacientes é relacional e participativo, não cabendo mais uma prática verticalizada. É necessário pensar a clínica de enfermagem dotada de especificidade, contudo, norteada por uma atitude transdisciplinar.

A transdisciplinaridade é uma abordagem que passa entre, além e através das disciplinas, numa busca de compreensão da complexidade. ${ }^{27}$ Pensar em transdisciplinaridade significa operar com distintos saberes de modo dinâmico e participativo em conjunto com a sociedade, a cultura, a religião, as vivências dos sujeitos, aplicados à especificidade do cuidado de enfermagem. Os acadêmicos trazem à tona esta compreensão.

Sei que é importante saber a localização das bulhas cardiacas. Mas também acho importante perceber o que na vida daquele indivíduo faz com ele se estresse e altere os batimentos. [...] para não somente dizer "Seu fulano, o senhor está com taquicardia". Nisso a gente ajuda descobrindo a causa e ajudando no tratamento (A18).
No ensino do exame físico, a transdisciplinaridade favorece o uso da tecnologia leve-dura, descrita anteriormente, pois possibilita lidar, concomitantemente, com a objetividade e a subjetividade. O acadêmico poderá refletir e criticar, executando a técnica de forma eficiente e relacioná-la à descoberta dos campos que interagem na produção de saúde e doença, o contexto social e cultural dos sujeitos.

\section{CONSIDERAÇÕES FINAIS}

O estudo propôs idéias, reflexões e críticas, à medida que descreveu como vem sendo realizado o exame físico no curso de graduação de enfermagem. Busca-se um saber-fazer reflexivo que atenda aos contextos atuais da educação e da saúde. As ferramentas oferecidas visam o empreendimento de medidas transformadoras no ensino de graduação em enfermagem exaltando a construção conjunta, considerando as técnicas, tecnologias e a subjetividade, além de considerar os eventos inesperados que possam surgir durante a interação entre o enfermeiro e o paciente.

O momento é de reorientação da formação em saúde, da construção de um novo modelo de cuidado e, consequentemente, oportuno para a reflexão a respeito do processo de ensino-aprendizagem na enfermagem. Neste sentido, a atuação do professor é fundamental, particularmente, quando são utilizadas estratégias de interação com os acadêmicos.

É possível ao enfermeiro realizar o exame físico a partir de uma visão mais abrangente do que aquela que pressupõe que tudo o que se afasta do modelo idealizado deve sofrer intervenção. Tratase de um processo lento e, não raro, acompanhado de instabilidades e contrariedades. A ampliação do foco da compreensão sobre a realização do exame físico contribui para se colocar em prática os novos enunciados e visibilidades de um paradigma emergente na saúde que considera a complexidade, a transdisciplinaridade e a relevância das ações de enfermagem na sociedade.

Durante o processo de ensino-aprendizagem do exame físico, são viáveis as junções dinâmicas entre as técnicas semiológicas, a subjetividade e os atravessamentos na clínica, desenvolvendo a tecnologia leve-dura.

O saber passa a ser construído em conjunto, possibilitando a participação de acadêmicos, professores, monitores e pacientes, e, conseqüentemente, a qualidade do ensino e assistência. 
É necessário o exercício da arte no cuidado, dotada da sensibilidade estética e da ética, considerando a humanização e a complexidade na saúde.

Enfim, a pedagogia proposta por esse estudo considera os valores da técnica, do olhar complexo e do acolhimento em busca da transdisciplinaridade e consolidação dos cuidados clínicos em enfermagem, que aqui se circunscreveu no ensino do exame físico.

\section{REFERÊNCIAS}

1. Teixeira ER. O Ético e O Estético nas Relações de Cuidado em Enfermagem. Texto Contexto Enferm. 2005 Jan-Mar; 14(1)89-95.

2. Daolio J; Velozo ELA. Técnica Esportiva como Construção Cultural: Implicações para a Pedagogia do Esporte. Pensar a Prática. 2008 Jan-Jul; 11(1):9-16.

3. Queiroz MS. O paradigma mecanicista da medicina ocidental moderna: uma perspectiva antropológica. Rev Saúde Pública. 1986 Ago; 20(4):309-17.

4. Maturana HR. Da biologia à psicologia. $3^{\mathrm{a}}$ ed. Porto Alegre (RS): Artes Médicas; 1998.

5. Teixeira ER. A Crítica e a sensibilidade no Processo de Cuidar na Enfermagem. Esc Anna Nery Rev Enferm. 2004 Dez; 8(3):361-9.

6. Merhy EE. A perda da dimensão cuidadora na produção da saúde: uma discussão do modelo assistencial e de intervenção no seu modo de trabalhar a assistência. In: Reis AT, Santos AF, Campos CC, Malta DC, Merhy EE. Sistema Único de Saúde em Belo Horizonte: reescrevendo o público. São Paulo (SP): Xamã; 1998. p.103-20.

7. Figueiredo NMA. Fundamentos do Uso de técnicas e tecnologias na enfermagem. São Caetano do Sul (SP): Yendis Editora; 2006.

8. Teixeira ER. A questão de eros na filosofia do cuidado com o corpo. Texto Contexto Enferm. 2006; 15(Esp):186-92.

9. Minayo MCS. Pesquisa social: teoria, método e criatividade. Rio de Janeiro (RJ): Vozes; 2002.

10. Figueiredo NM. A. Método e Metodologia da Pesquisa Científica. São Paulo (SP): Difusão; 2004

11. Leopardi MT. Metodologia da Pesquisa na Saúde. Santa Maria (RS): Palloti; 2001.

Correspondência: Carlos Magno Carvalho da Silva

Rua Dr. Porciúncula, 840

28685-000 - Japuíba, Cachoeiras de Macacu, RJ, Brasil

E-mail: mcarvalho27@yahoo.com.br
12. Minayo MCS. O desafio do conhecimento: pesquisa qualitativa em saúde. São Paulo (SP): Hucitec; 2004.

13. Eugenio SCF. Semiologia para a enfermagem: sinais e signos, o que sabemos, o que fazemos [dissertação]. Rio de Janeiro (RJ): Universidade Federal do Rio de Janeiro. Centro de Ciências Biológicas e da Saúde; 1998.

14. Montagu A. Tocar: o significado humano da pele. São Paulo (SP): Summus; 2002.

15. Stefanelli MC. Comunicação com o paciente: teoria e ensino. São Paulo (SP): Robe Editorial, 1993.

16. Silva MJP. Comunicação tem remédio: a comunicação nas relações interpessoais em saúde. São Paulo (SP): Gente; 1996.

17. Maria VLR, organizador. Exame Clínico de Enfermagem do Adulto. São Paulo (SP): Iátria; 2003.

18. Orlando IJ. O Relacionamento dinâmico enfermeiro/ paciente: função, processo e princípios. $4^{\mathrm{a}}$ ed. São Paulo (SP): EPU; 2004.

19. Ramos DD; Lima, MADS. Acesso e acolhimento aos usuários em uma unidade de saúde de Porto Alegre, Rio Grande do Sul, Brasil. Cad Saúde Pública. 2003 Jan-Fev, 19(1):27-34.

20. Braga EM; Silva MJP. Comunicação competente: visão de enfermeiros especialistas em comunicação. Acta Paul Enferm. 2007. Out-Dez, 20(4):410-14.

21. Seel, M. A libertação da estética filosófica por Kant. Tradução: Alfred Keller. [artigo da Internet] GoetheInstitut; 2004 fev [acesso 2008 Dez 13]. Disponível em: http://www.goethe.de/br/sap/kultur/ ano_kant.htm\#E3

22. Waldow VR; Borges RF. O processo de cuidar sob a perspectiva da vulnerabilidade. Rev Latino-am Enfermagem. 2008 Jul-Ago; 16(4):765-71.

23. Teixeira ER; Figueiredo, NMA. Odesejo e a necessidade no Cuidado com o Corpo. Niterói (RJ): EdUFF, 2001.

24. Caponi S. Da compaixão à solidariedade: uma genealogia da assistência médica. Rio de Janeiro (RJ): FIOCRUZ; 2000.

25. Saboia VM. Educação em Saúde: A Arte de talhar pedras. Niterói (RJ): Intertexto; 2003.

26. Luiz DI, Damkauskas T, Ohl RIB. A. A Importância da relação aluno-professor na vivência do exame físico em Enfermagem: um enfoque fenomenológico. Acta Paul Enferm. 1997 Set-Dez; 10(3):62-72.

27. Nicolescu B. O Manifesto da Transdisciplinaridade. Coleção Trans. São Paulo (SP): Triom; 2001. 